\title{
Endometriosis of the Bladder
}

\author{
Mesanenin Endometriozisi
}

\section{Zübeyde Yıldırım Ekin}

Tepecik Training and Research Hospital, Clinic of Pathology, Izmir Turkey

\section{Introduction}

Endometriosis is characterized by the presence of functional endometrial tissue outside the uterus. Endometriosis is common entity, but the involvement of the urinary tract is rare (1). Although endometriosis frequently occurs in women of reproductive age, bladder endometriosis is an uncommon condition (approximately $1 \%$ of all endometriosis cases). On the other hand, the bladder is the most affected organ in the urinary tract (2). Two forms of bladder endometriosis have been defined: One occurs in women without a history of uterine surgery (primary), and the other one develops after pelvic operation (iatrogenic or secondary) (3). The average age of cases is approximately 35 years. Frequency, hematuria, dysuria and urgency are the most common symptoms, however, approximately $50 \%$ of patients are asymptomatic. Severity of symptoms is related to the size of endometriotic lesions and the location. Endometriosis

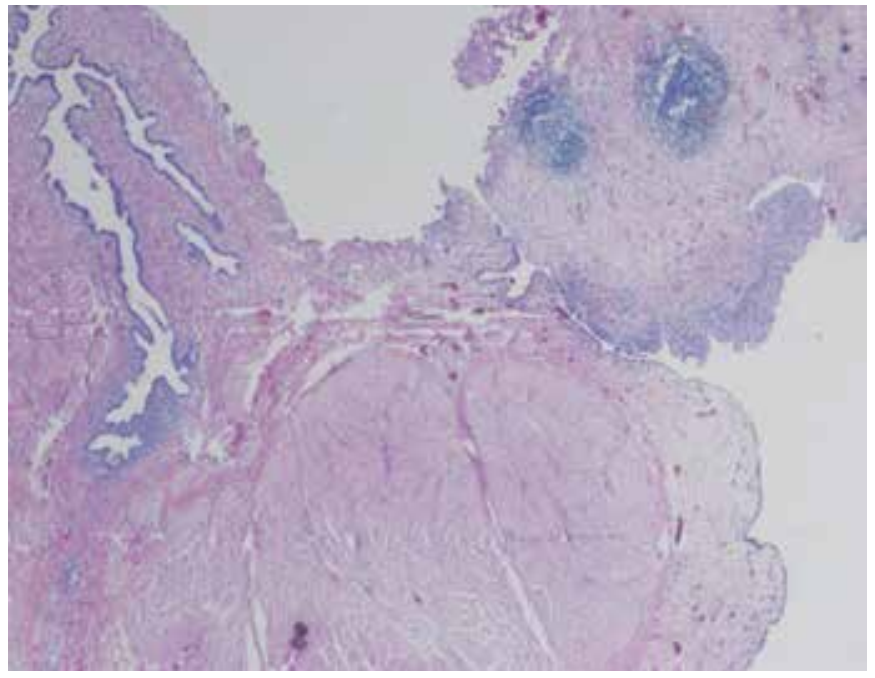

Figure 1. Several irregularly shaped endometrial glands surrounded by endometrial stroma adjacent to a detrusor muscle bundle. The glandular epithelium lacks cytologic atypia and mitotic activity of the muscularis propria may show similar symptoms to those of interstitial cystitis. There is a palpable suprapubic mass in almost 50\% of cases, and it may undergo catamenial expansion. Therefore, it must be kept in mind in the differential diagnosis of hematuria especially in female patients in the reproductive age $(4,5)$. Rarely, endometriosis has been described in postmenopausal female patients treated with estrogen, likewise in men treated with hormone therapy for prostate cancer (5). Cystoscopic examination of endometriosis reveals edematous, erythematous mucosal elevations overlying blue-black or red-blue cysts, a grossly hemorrhagic, ill-defined, polypoid lesion. The overlying urothelium sometimes may be eroded. If the lesions are located in the muscularis propria or serosa, the mucosa may be intact. The bladder wall around the lesion may be thickened because of hyperplasia and fibrosis (1). Microscopically, the lesion is consisted of endometrial glands and stroma which is identical endometriosis as seen elsewhere (Figure 1). The diagnosis depends on identification

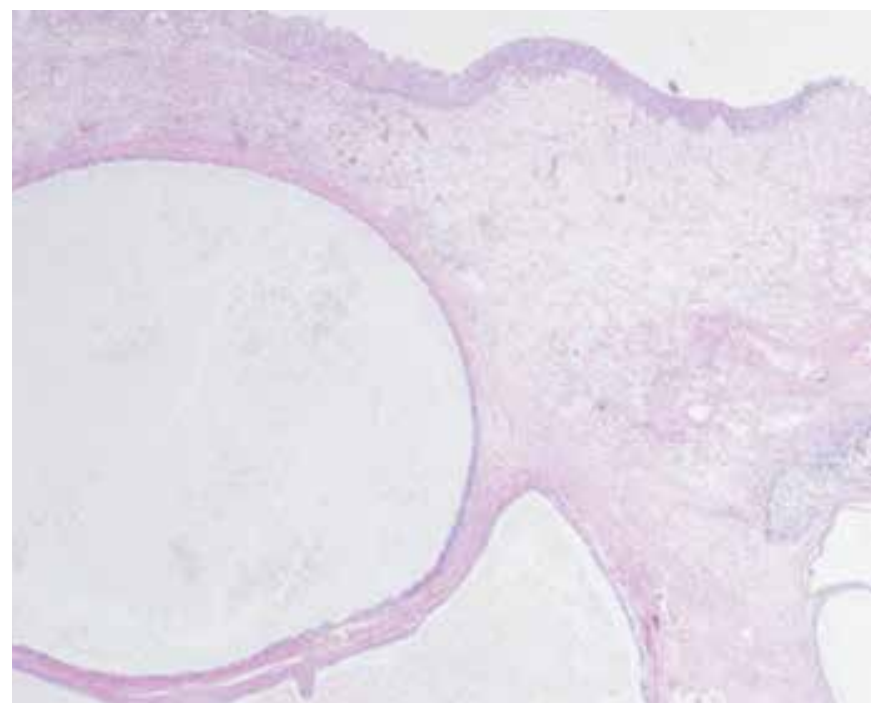

Figure 2. Glands lined by flattened epithelium with luminal eosinophilic, proteinaceous material located under the urothelium

\section{Correspondence}

Zübeyde Yıldırım Ekin MD, Tepecik Training and Research Hospital, Clinic of Pathology, İzmir, Turkey

Phone: +90 5068524533 E-mail: zubeydeyildirimekin@gmail.com Received: 03.05.2016 Accepted: 03.05.2016 


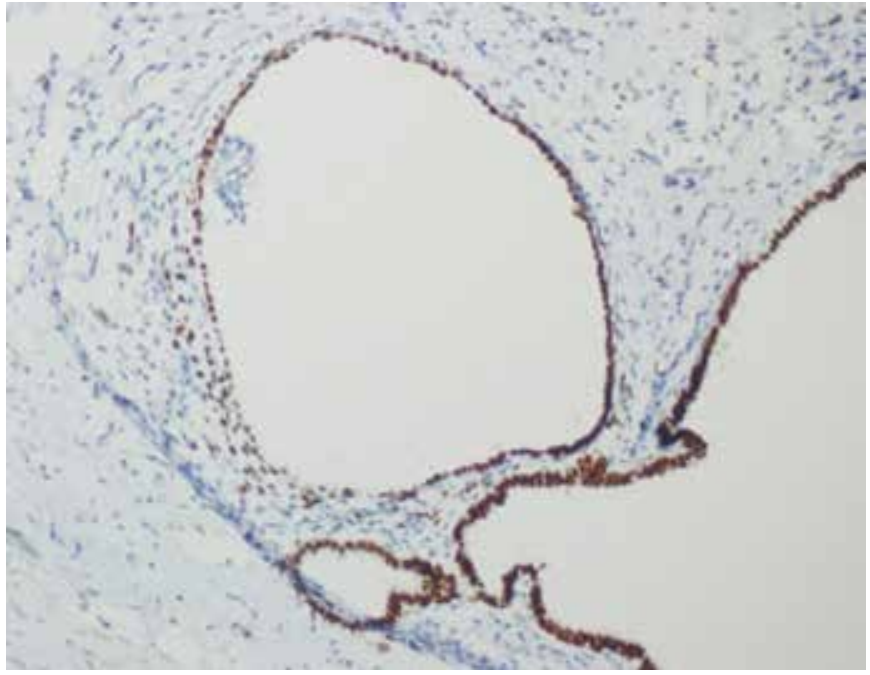

Figure 3. Immunostains for estrogen receptor is nuclear positive in epithelial cells lining the endometriotic glands

of two of the three criteria: endometrial stromal cells, endometrial glands, and recent or old hemorrhage (Figure 2). Sometimes AriasStella reaction, endometrial hyperplasia or malignant transformation can be seen in endometriosis. Immunohistochemically, endometriosis shows expression of epithelial cells for CK7, CA125, estrogen receptor, and progesterone receptor as well as CD10 expression within stroma (Figure 3,4). These immunohistochemical markers may be helpful in diagnostically challenging cases (2). Endometriosis is rare entity which should be kept in mind in the differential diagnosis of primary invasive adenocarcinoma of the bladder, especially when it involves muscularis propria.

\section{Ethics}

Peer-review: Internal peer-reviewed.

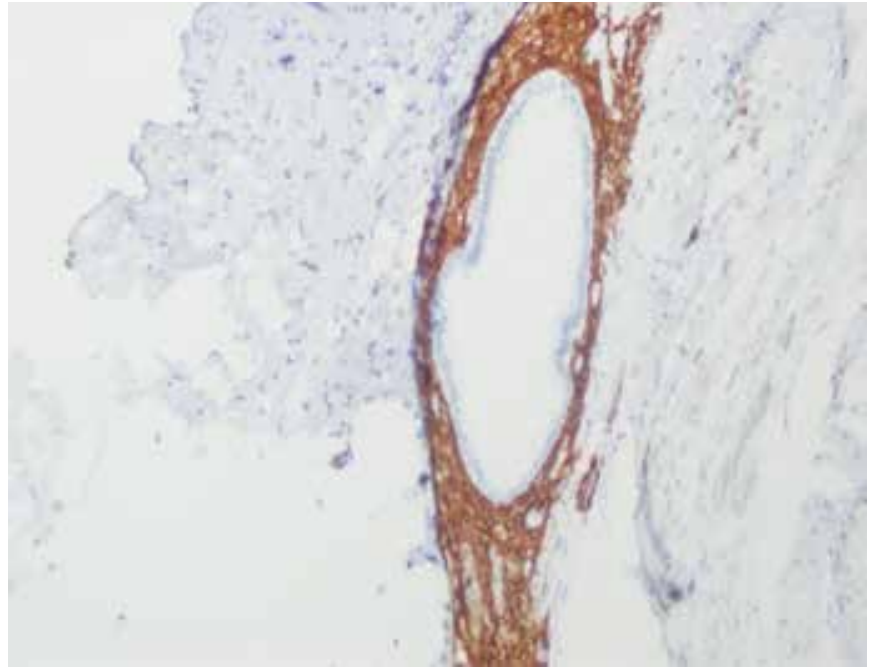

Figure 4. The endometrial stromal cells highlighted by CD10 immunostaining

\section{References}

1. Gupta A, Bhatnagar A, Seth BN, Dang A, Gupta V. Bladder endometriosis mimicking TCC-a case report. J Clin Diagnostic Res 2016;10:12-13.

2. Al-Khawaja M, Tan PH, MacLennan GT, Lopez-Beltran A, Montironi R, Cheng L. Ureteral endometriosis: clinicopathological and immunohistochemical study of 7 cases. Hum Pathol 2008;39:954-959.

3. Donnez J, Spada F, Squifflet J, Nisolle M. Bladder endometriosis must be considered as bladder adenomyosis. Fertil Steril 2000;74:1175-1181.

4. Bulut $S$, Aktaş BK, Özden $C$, Erkmen $A E$, Güreş̧̧i $S$, Kulaçoğlu $S$, Memiş A. A case of primary bladder endometriosis who had undergone partial cystectomy. 2014;21:157-159.

5. Oliker AJ, Harris AE. Endometriosis of the bladder in a male patient. J Urol 1971;106:858-859. 